\section{ProduÇão CIENTÍFICA: CRITÉRIOS DE AVALIAÇÃO DE IMPACTO}

Considerando que o periódico ainda é um dos canais mais utilizados para a comunicação de pesquisa científica, nota-se, nos últimos anos, uma preocupação por hierarquizar as revistas científicas e avaliar o número de citações por parte dos órgãos de fomento, no julgamento de projetos, na concessão de bolsas de estudo e na avaliação de cursos de pós-graduação.

No Brasil, a discussão sobre a freqüência com que um pesquisador é citado ganhou importância quando a Folha de $S$. Paulo, no caderno Mais, de 21 de maio de 1995, publicou a relação dos 170 pesquisadores em atividade no país com mais de 200 citações na literatura internacional entre 19811993. Esta relação foi extraída do Science Citation Index do Institute for Scientific Information (ISI), que desde 1986 usa dois critérios na escolha das revistas que compõem a base de dados: a periodicidade e o impacto da revista, que é medido pelo número de citações de seus artigos em outras revistas!

Cerca de 8 mil títulos de periódicos estão indexados no $|S|$ divididos em três grandes áreas: Science Citation Index Expanded, Social Sciences Citation Index e Arts \& Humanities Citation Index.

O ranking dos periódicos pelo fator de impacto é publicado pelo Journal Citation Reports (JCR), publicação anual criada em 1975, que oferece recursos para a avaliação dos títulos que compõem a base da Web of Science. Este fator de impacto é definido matematicamente como o número de vezes que os artigos das revistas são citados durante um período específico (o numerador), dividido pelo número total de artigos publicados por esta revista no mesmo período (denominador), num período convencional de dois anos.
Não há como medir quanto um artigo foi utilizado pelos profissionais, mas podese medir seu efeito para outros pesquisadores e autores, examinando com que freqüência e onde foram citados em outros artigos.

O JCR é importante ferramenta auxiliar tanto para o pesquisador, que poderá determinar onde deve publicar seus trabalhos, assim como para os bibliotecários realizarem análise de coleção de periódicos.

O Brasil, que é responsável por mais de $1 \%$ da produção científica mundial, conta com 16 títulos de periódicos cujos fatores de impacto são avaliados pelo ISI.

No âmbito brasileiro, a BIREME (Centro Latino-Americano e do Caribe de Infor-

\begin{tabular}{|l|c|}
\hline Título & Fator de impacto \\
\hline Arquivo Brasileiro de Medicina Veterinária e Zootecnia & 0.057 \\
\hline Arquivos de Neuropsiquiatria & 0.197 \\
\hline Brazilian Journal of Medical and Biological Research & 0.654 \\
\hline Brazilian Journal of Physics & 0.671 \\
\hline Computational and Applied Mathematics & 0.375 \\
\hline Eclética Química & 0.100 \\
\hline Genetics and Molecular Biology & 0.470 \\
\hline Journal of the Brazilian Chemical Society & 0.402 \\
\hline Memórias do Instituto Oswaldo Cruz & 0.542 \\
\hline Pesquisa Agropecuária Brasileira & 0.084 \\
\hline Pesquisa Veterinária Brasileira & 0.409 \\
\hline Química Nova & 0.399 \\
\hline Revista Brasileira de Zootecnia & 0.027 \\
\hline Revista de Microbiologia & 0.073 \\
\hline Revista de Saúde Pública & 0.226 \\
\hline Dados: Revista de Ciências Sociais & 0.167 \\
\hline
\end{tabular}

Fonte: JCR, 2000 
mação em Ciências da Saúde) é responsável pelo Scientific Library on Line (SCIELO/ http://www.scielo.br), que reúne 68 publicações científicas brasileiras. "Sua interface permite o acesso fácil aos textos completos de artigos científicos, por meio das tabelas de conteúdo dos números individuais das revistas ou da recuperação de textos por nome de autor, palavras-chaves, palavras do título ou do resumo. Publica também relatórios atualizados do uso e impacto da coleção e dos títulos individuais das revistas. Os artigos são enriquecidos com enlaces dinâmicos a bases de dados bibliográficas nacionais e internacionais e à Plataforma Lattes no CNPq. É um produto cooperativo entre a FAPESP, a BIREME/OPAS/OMS e editores científicos brasileiros, iniciado em 1997, com o objetivo de tornar mais visível, mais acessível e incentivar a consulta das mais conceituadas revistas brasileiras?. "

Recentemente, o SCIELO recebeu reconhecimento internacional na sua missão de promover o aumento da visibilidade, acessibilidade e credibilidade das publicações científicas produzidas no Brasil, América Latina e Caribe. Um estudo feito por dois pesquisadores da Universidade de Oxford, e publicado na revista Nature 415:47/ -2, de 31 de janeiro de 2002, comprovou que o fator de impacto de cinco periódicos brasileiros indexados no ISI teve um aumento médio de 132,7\%4.

A CAPES (Fundação Coordenação de Aperfeiçoamento de Pessoal de Nível Superior) adota oficialmente o fator de impacto das revistas científicas para a avaliação dos professores, cursos e das instituições inscritas na CAPES que oferecem curso de pósgraduação. Seguindo o modelo do JCR, disponibiliza on-line o Qualis Internacional para a classificação dos periódicos internacionais e o "Qualis Nacional com níveis A, B e $C$ de acordo com critérios de indexação, sendo: a) Qualis Nacional A: todos aqueles que se encontram indexados em pelo menos um dos seguintes indexadores internacionais: Medline, Embase, Web of Science, Scielo e outras bases de dados referenciais reconhecidas pela CAPES (Biological Abstracts, CAB Abstracts, Compendex, DII, Econlit, FSTA-Food Science and Technology Abstracts, GEOREF, MLA-Modern Language Association, Sociological Abstracts, WoS, High Wire Press, Ideal-Editora Academic Press, OVID, Editora Elsevier) ou num outro indexador internacional, o mais representativo da área; b) Qualis Nacional B: aqueles indexados no LILACS ou que sejam editados por sociedades científicas nacionais representativas da área; c) Qualis C: os demais periódicos que não atendam os critérios acima". (Disponível em: < http:/ /www.fop.unicamp.br/biblioteca/AVALIA200 I-pg.htm> em 04 fev. 2002)

De um modo geral, os Comitês de Avaliação das agências de fomento incentivam a publicação científica pelo imperativo "publicar ou perecer", considerando a quantidade de artigos publicados em detrimento da qualidade dos mesmos².

$\mathrm{Na}$ busca da qualidade dos programas de pós-graduação, as instituições deveriam contemplar disciplinas de apoio e orientaçãa para a confecção e divulgação da produção bibliográfica científica, objetivando a qualidade dos artigos e das publicações. Do mesmo modo, as bibliotecas destas instituições e seus profissionais têm papel preponderante na organização e disseminação dos conhecimentos ali gerados.
Pinto e Andrade ${ }^{2}$ ressaltam que os periódicos no terceiro mundo tendem a apresentar baixos fatores de impacto por motivos variados: dificuldade de acesso aos periódicos, precariedade de títulos assinados pelas instituições ou ainda outros fenômenos como a preferência dos pesquisadores por periódicos internacionais com bom fator de impacto e a citação por parte dos pesquisadores de colegas estrangeiros e não brasileiros. Podemos acrescentar ainda como motivo para o baixo impacto dos periódicos nacionais a diversidade de condições das instituições de ensino nacionais em função das diferenças regionais, culturais e socioeconômicas.

No universo hipotético de um milhão de revistas e por volta de 4.600 títulos de periódicos brasileiros, a quantidade de revistas nacionais indexadas no ISI representa, sem deixar dúvidas, um indicador de competência e inserção do país no cenário da ciência mundial.

ILHENA

Maria fazanelli Crestana Serviço de Biblioteca de Documentação Faculdade de Medicina da Universidade de São Paulo

\section{Referências}

I. Targino MG, Garcia JCR. Ciência brasileira na base de dados do Institute for Scientific Information (ISI). Ci. Inf. Brasilia 2000, 29:103-17.

2. Pinto AC, Andrade JB. Fator de impacto de revistas científicas: qual o significado deste parâmetro? Química Nova 1999 , 22:448-53.

3. SCIELO. Pesquisa FAPESP 2002, 72:8.

4. SciELO News [Online]. n.I fev./2002. 